\title{
Pre-compensation for a Hybrid Fuzzy PID Control of a Proportional Hydraulic System
}

\author{
Pornjit Pratumsuwan and Chaiyapon Thongchaisuratkrul \\ King Mongkut's University of Technology North Bangkok \\ Thailand
}

\section{Introduction}

Fluid power is a term which was created to include the generation, control, and application of smooth, effective power of pumped or compressed fluids when this power is used to provide force and motion to mechanisms. Fluid power includes hydraulic, which involves liquids, and pneumatic, which involves gases. Hydraulic and pneumatic power offer many advantages over electric motors, especially for systems that require high speed linear travel, moving or holding heavy loads, or very smooth position or pressure control. Compared to other types, hydraulic and pneumatic actuators are smaller and quieter. They also produce less heat and electromagnetic interference (EMI) at the machine than do electric actuators, and in many cases, in particular with high performance hydraulic or pneumatic system, they offer the ability to build machines at considerable savings compared to machines employing purely electrical or mechanical motion (Chuang \& Shiu, 2004; Knohl \& Unbehauen, 2000).

Hydraulic drives, thanks to their high power intensity, are low in weight and require a minimum of mounting space. They facilitate fast and accurate control of very high energies and forces. The hydraulic actuator (cylinder) represents a cost-effective and simply constructed linear drive. The combination of these advantages opens up a wide range of applications. The increase in automation makes it ever more necessary for pressure, flow rate, and flow direction in hydraulic systems to be controlled by means of an electrical control system. The obvious choice for this is hydraulic proportional valves (or servo valves) as an interface between controller and hydraulic system (Knohl \& Unbehauen, 2000).

The hydraulic actuator, usually a cylinder, provides the motion of the load attached to the hydraulic system. A control valve meters the fluid into the actuator as a spool traverses within the valve body. The control valve is either a servo valve or a proportional valve. In hydraulic control applications, proportional valves offer various advantages over servo valves (Eryilmaz \&. Wilson, 2006). Proportional valves are much less expensive. They are more suitable for industrial environments because they are less prone to malfunction due to fluid contamination. In addition, since proportional valves do not contain sensitive, precision components, they are easier to handle and service. However, these advantages are offset by their nonlinear response characteristics. Since proportional valves have less precise manufacturing tolerances, they suffer from performance degradation. The larger tolerances 
on spool geometry result in response nonlinearities, especially in the vicinity of neutral spool position. Proportional valves lack the smooth flow properties of "critical centre" valves, a condition closely approximated by servo valves at the expense of high machining cost. Small changes in spool geometry (in terms of lapping) may have large effects on the hydraulic system dynamics. Especially, a closed-centre spool (overlapped) of proportional valve, which usually provides the motion of the actuator in a proportional hydraulic system (PHS), may result in the steady state error because of its dead zone characteristics in flow gain [(Eryilmaz \&. Wilson, 2006). Figure 1 illustrates the characteristics of proportional valve.
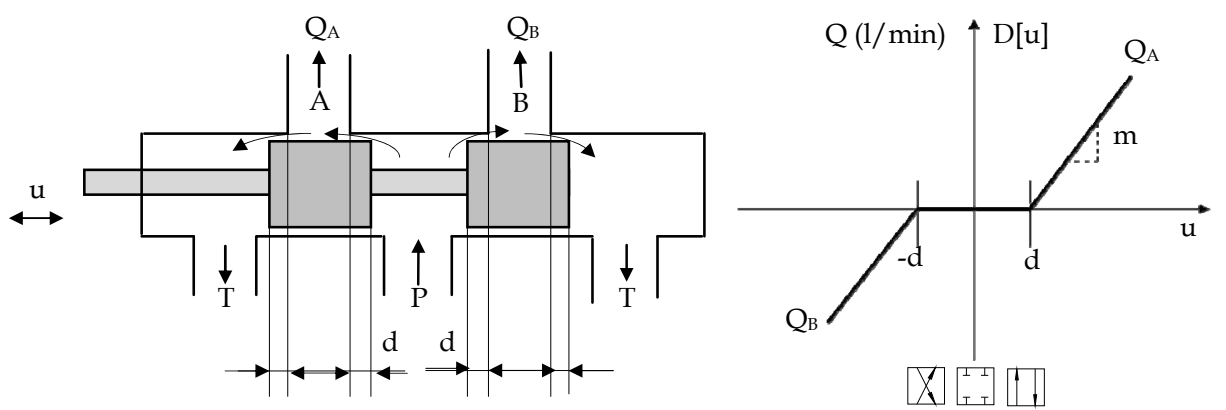

Fig. 1. Characteristics of a closed-centre spool (overlapped) of proportional valve.

Valve lap, or valve overlap, refers to the amount of spool travel from the center position required to start opening between the powered input port and the work (output) port or the tank port. A zero lapped valve is one in which any tiny, differentially small amount of spool shift, either way, starts the opening. However, there is no contact between the OD of the spool and ID of the bore. And even zero lapped valves have some slight amount of overlap. Nonetheless, the zero lapped term persists.

The characteristics of the proportional valve with dead zone $D$ (from figure 1 ) is described by the function

$$
\mathrm{Q}=\mathrm{D}[\mathrm{u}]= \begin{cases}\mathrm{m}(\mathrm{u}-\mathrm{d}), & \text { if } \mathrm{u} \geq \mathrm{d} \\ 0, & \text { if }-\mathrm{d} \leq \mathrm{u} \leq \mathrm{d} \\ \mathrm{m}(\mathrm{u}+\mathrm{d}), & \text { if } \mathrm{u}<-\mathrm{d}\end{cases}
$$

where $d, m \geq 0$. The parameter $2 d$ specifies the width of the deadzone, while $m$ represents the slope of the response outside the dead zone.

The proportional hydraulic system shown in figure 2 is comprised of a double acting cylinder, a 4/3 way proportional valve, and load. The supply pressure $\mathrm{P}$ is assumed to be constant, and the control objective is the positioning of the pay load. The proportional valve used in this plant is a low cost, which can be characterized by a relative large and symmetric dead zone. A complete mathematic model of such an electro-hydraulic system, for example, has been given by (Knohl \& Unbehauen, 2000). However, these equations are highly complex and difficult to utilize in control design. A more practical model may be obtained through the linearization of the non-linear function. 


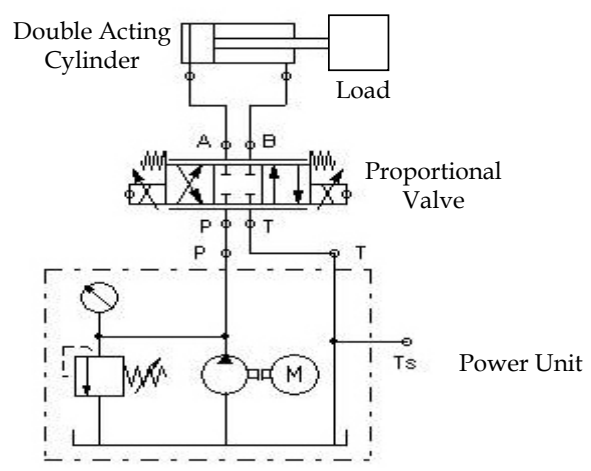

Fig. 2. Schematic diagram of the PHS.

A mathematical model of the plant can be derived from the flow equation of valve, the continuity equation and balance of forces at the piston. The valve flow rate equation is highly non-linear and dependent on the valve displacement from neutral, which is proportional to input voltage $\mathrm{u}$ and the pressure drop across the load $\mathrm{P}_{\mathrm{L}}$. A Taylor series linearization leads to

$$
\mathrm{Q}_{\mathrm{L}}=\mathrm{K}_{\mathrm{q}} \mathrm{u}-\mathrm{K}_{\mathrm{c}} \mathrm{P}_{\mathrm{L}}
$$

where, $\mathrm{K}_{\mathrm{q}}=$ flow gain coefficient and $\mathrm{K}_{\mathrm{c}}=$ flow pressure coefficient

The movement of the piston, the change of the oil volume due to compressibility and the leakage oil flow determine the total oil flow $Q_{L}$ as

$$
\mathrm{Q}_{\mathrm{L}}=\mathrm{A}_{\mathrm{P}} \dot{\mathrm{y}}+\frac{\mathrm{V}_{\mathrm{t}}}{4 \beta_{\mathrm{e}}} \dot{\mathrm{P}}_{\mathrm{L}}+\mathrm{f}\left(\mathrm{P}_{\mathrm{L}}\right)
$$

where, $V_{t}$ is the total compressed oil volume, $A_{P}$ the surface area of the piston, $\dot{y}$ the velocity of the piston, $\beta_{\mathrm{e}}$ the effective bulk modulus (compressibility) and $f\left(P_{\mathrm{L}}\right)$ the non linear influence of the internal and external oil leakage. Here, it is assumed that the rod and the head side areas of the piston are equal. If the leakage function is approximated by a linear relation, equation (3) can be rewritten as

$$
\dot{\mathrm{P}}_{\mathrm{L}}=\frac{4 \beta_{\mathrm{e}}}{\mathrm{V}_{\mathrm{t}}}\left(\mathrm{Q}_{\mathrm{L}}-\mathrm{C}_{\mathrm{tp}} \mathrm{P}_{\mathrm{L}}-\mathrm{A}_{\mathrm{p}} \dot{\mathrm{y}}\right.
$$

where $C_{t p}$ is the total leakage coefficient of the piston. The balance of forces at the sliding carriage leads to

$$
\mathrm{F}_{\mathrm{G}}=\mathrm{A}_{\mathrm{p}} \mathrm{P}_{\mathrm{L}}=\mathrm{M}_{\mathrm{t}} \ddot{\mathrm{y}}+\mathrm{B}_{\mathrm{p}} \dot{\mathrm{y}}+\mathrm{y}
$$

where $F_{G}$ is the force generated by the piston, $M_{t}$ the total mass of the piston and the load, and $B_{p}$ the damping coefficient of the piston and the load. Neglect the non linear effects of dry and adhesive friction, combining equations (2), (4), and (5) and applying the Laplace transformation to the resulting third order differential equation results in the transfer function 
where the abbreviations

$$
\frac{Y(s)}{u(s)}=\frac{b_{0}}{s\left(a_{2} s^{2}+a_{1} s+a_{0}\right)}
$$

$$
\begin{aligned}
& \mathrm{b}_{0}=\frac{4 \beta_{\mathrm{e}}}{\mathrm{V}_{\mathrm{t}}} \mathrm{K}_{\mathrm{q}} \\
& \mathrm{a}_{0}=\frac{4 \beta_{\mathrm{e}}}{\mathrm{V}_{\mathrm{t}}}\left(\frac{\mathrm{B}_{\mathrm{p}}}{\mathrm{A}_{\mathrm{p}}}\left(\mathrm{K}_{\mathrm{C}}+\mathrm{C}_{\mathrm{tp}}\right)+\mathrm{A}_{\mathrm{p}}\right) \\
& \mathrm{a}_{1}=\frac{\mathrm{B}_{\mathrm{p}}}{\mathrm{A}_{\mathrm{p}}}+\frac{4 \beta_{\mathrm{e}} \mathrm{M}_{\mathrm{t}}}{\mathrm{V}_{\mathrm{t}} \mathrm{A}_{\mathrm{p}}}\left(\mathrm{K}_{\mathrm{C}}+\mathrm{C}_{\mathrm{tp}}\right) \\
& \mathrm{a}_{2}=\frac{\mathrm{M}_{\mathrm{t}}}{\mathrm{A}_{\mathrm{p}}}
\end{aligned}
$$

The parameters of the linear model of the hydraulic system given by equation (7), which depend on the constants derived by linearization, are all of varying nature. Variation of the load mass and the damping coefficient can also be interpreted as parameter changes of the linear model. To take the dead zone of the actuating valve into account, a static non linear dead zone that is portrayed in figure 1.

\section{Preliminary of Controller Designs}

A closed loop system, whither the reference signal is set manually or automatically, can perform control of cylinder position, speed and force. Figure 3 represents typical of an "Automatic Closed Loop" control system. As shown in the figure, the position of a hydraulic cylinder is controlled by a proportional valve. The proportional valve solenoid is receiving driving electrical current from an amplifier card, which is generating the driving current based on a control signal supplied by a controller. The controller responsibility is to continuously compare the reference signal and the actual cylinder position fed back by the position sensor, after consequently generate the adequate control signal.

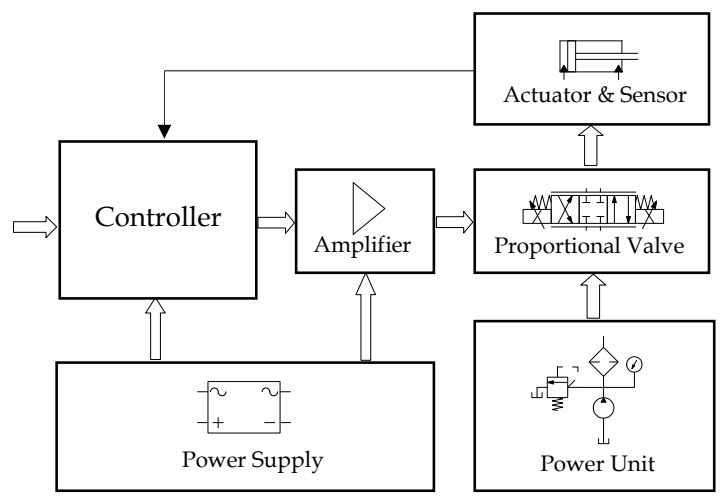

Fig. 3. Conceptual controls of the PHS. 


\subsection{PID controller}

Classical PID controllers are very popular in industries because they can improve both the transient response and steady state error of the system at the same time (Kim et al., 1994). Although great efforts have been devoted to develop PID controller, PID controllers are not robust to the parameter variation to the plants being controlled. Figure 4 shows the use of PID controller controls the PHS.

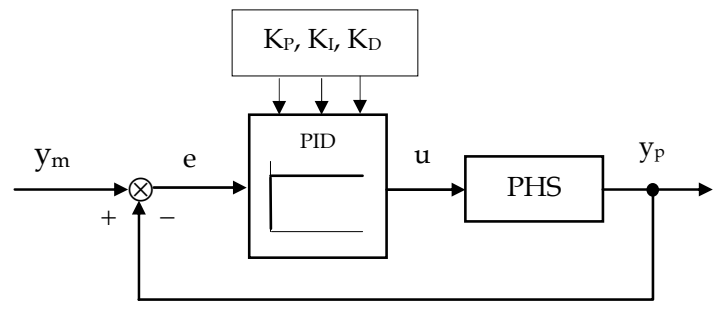

Fig. 4. Block diagram of a PID controller.

The PID control method has been widely used in industry during last several decades because of its simplicity. The implementation of PID control logic, as shown in equation (8), requires finding suitable values for the gain parameters $K_{P}, K_{I}$, and $K_{D}$. To tune these parameters, the model is linearized around different equilibrium points,

$$
\mathrm{u}(\mathrm{k})=\mathrm{K}_{\mathrm{P}} \mathrm{e}(\mathrm{k})+\mathrm{K}_{\mathrm{I}} \sum_{\mathrm{i}=0}^{\mathrm{k}} \mathrm{e}(\mathrm{i})+\mathrm{K}_{\mathrm{D}}[\mathrm{e}(\mathrm{k})-\mathrm{e}(\mathrm{k}-1)]
$$

where $\mathrm{e}(\mathrm{k})$ is the error signal. However, the PID method is not suitable for controlling a system with a large amount of lag, parameter variations, and uncertainty in the model. Thus, PID control logic cannot accurately control position in a hydraulic system.

\subsection{Fuzzy logic controller}

Fuzzy logic control (FLC) has found many applications in a variety of fields since Prof. Zadeh introduced fuzzy set theory in 1965 (Zadah, 1965). Among the most successful applications of this theory has been the area of FLC initiated by the work of (Mamdani \& Assilian, 1975). FLC has the advantage that it does not require an accurate mathematical model of the process. It uses a set of artificial rules in a decision-making table and calculates an output based on the table. Figure 5 shows specific components characteristic of a FLC. Input variables go through the fuzzification interface and are converted to linguistic variables. Then, a database and rule base holding the decision-making logic are used to infer the fuzzy output. Finally, a defuzzification method converts the fuzzy output into a signal to be sent out.

Fuzzy control is robust to the system with variation of system dynamics and the system of model free or the system which precise information is not required. It has been successfully used in the complex ill-defined process with better performance than that of a PID controller. Another important advance of fuzzy controller is a short rise time and small overshoot (Li et al., 2006; Rahbari \& Silva, 2000). 
FLC has the advantage that it does not require an accurate mathematical model of the process. It uses a set of artificial rules in a decision-making table and calculates an output based on the table (Li et al., 2006; Rahbari \& Silva, 2000).

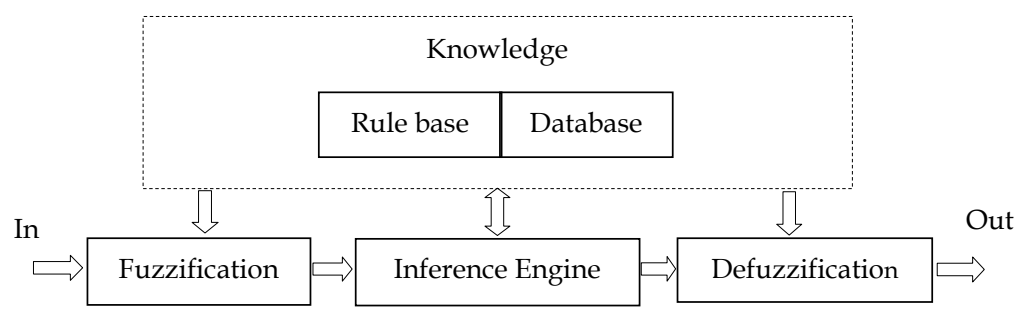

Fig. 5. Structure of FLC.

Figure 6 shows a fuzzy control of the PHS. Input variables go through the fuzzification interface and are converted to linguistic variables. Then, a database and rule base holding the decision-making logic are used to infer the fuzzy output. Finally, a defuzzification method converts the fuzzy output into a signal to be sent out.

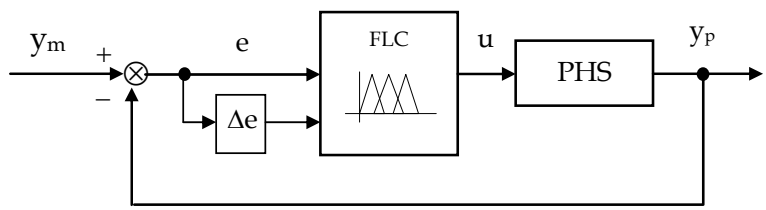

Fig. 6. Block digram of a FLC.

When used in a control system, FLC is robust since it provides a fast rise time and a small amount of overshoot. The control parameters and set of terms that describe each linguistic variable must be determined when designing a FLC. Obviously, the position in the electrohydraulic is the parameter to be controlled in the system. A two-dimension structure will be used to produce fast calculations. The two input linguistic variables are the error of the position (e) and the error change of the position $(\Delta \mathrm{e})$. The output is the voltage signal to control the amplifier and proportional valve. Thus, the FLC has two antecedences and one consequence.

The controller structure of a FLC, which the fuzzy states of the inputs and the output, all are chosen to be equal in number and use the same linguistic descriptors: $\mathrm{NB}=$ negative big, $\mathrm{N}$ = negative, $\mathrm{Z}=$ zero, $\mathrm{P}=$ positive, and $\mathrm{PB}=$ positive big. The fuzzy sets and its memberships function is shown in figure 7 . A set of fuzzy rules is shown in the Table 1.

Since the dynamics of each cylinder is not symmetric, due to the difference in the effective area of the rod side and the head side of the piston. The designed fuzzy set of the fuzzy controller accounts for this asymmetry as well (Rahbari \& Silva, 2000; Pratumsuwan \& Thongchai, 2009). 

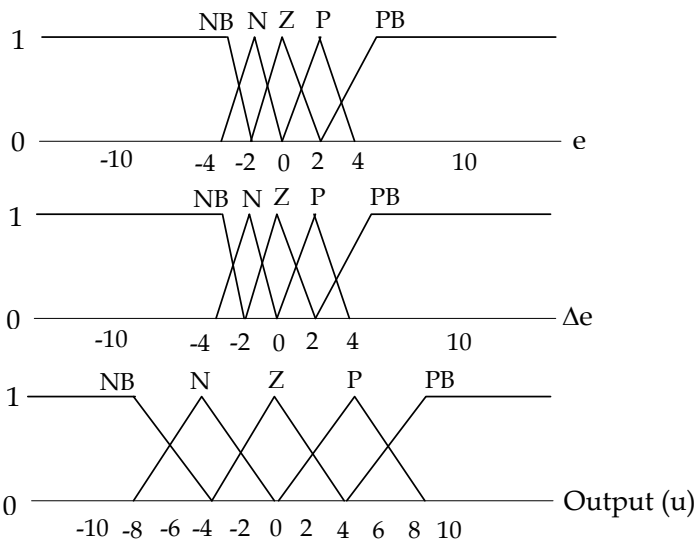

Fig. 7. Fuzzy sets of a FLC.

\begin{tabular}{|c|c|c|c|c|c|}
\hline $\mathrm{e}^{\Delta \mathrm{e}}$ & $\mathrm{NB}$ & $\mathrm{N}$ & $\mathrm{Z}$ & $\mathrm{P}$ & $\mathrm{PB}$ \\
\hline $\mathrm{NB}$ & $\mathrm{NB}$ & $\mathrm{NB}$ & $\mathrm{N}$ & $\mathrm{N}$ & $\mathrm{Z}$ \\
\hline $\mathrm{N}$ & $\mathrm{NB}$ & $\mathrm{N}$ & $\mathrm{N}$ & $\mathrm{Z}$ & $\mathrm{P}$ \\
\hline $\mathrm{Z}$ & $\mathrm{N}$ & $\mathrm{N}$ & $\mathrm{Z}$ & $\mathrm{P}$ & $\mathrm{P}$ \\
\hline $\mathrm{P}$ & $\mathrm{N}$ & $\mathrm{Z}$ & $\mathrm{P}$ & $\mathrm{P}$ & $\mathrm{PB}$ \\
\hline $\mathrm{PB}$ & $\mathrm{Z}$ & $\mathrm{P}$ & $\mathrm{P}$ & $\mathrm{PB}$ & $\mathrm{PB}$ \\
\hline
\end{tabular}

Table 1. Fuzzy Rules of a FLC.

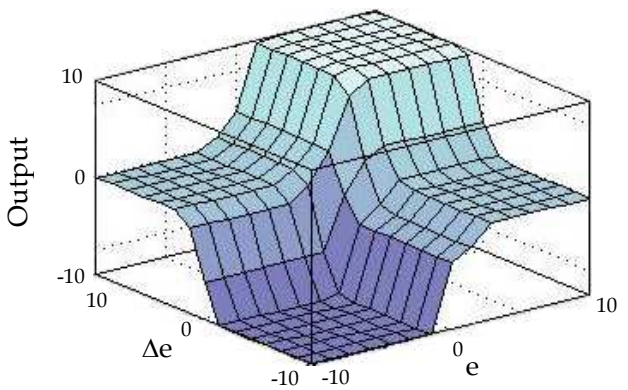

Fig. 8. Input-output mapping of a FLC.

\subsection{Hybrid of fuzzy and PID controller}

While conventional PID controllers are sensitive to variations in the system parameters, fuzzy controllers do not need precise information about the system variables in order to be effective. However, PID controllers are better able to control and minimize the steady state error of the system. Hence, a hybrid system, as shown in figure 9, was developed to utilize the advantages of both PID controller and fuzzy controller (Parnichkul \& Ngaecharoenkul, 2000; Erenoglu et al., 2006; Pratumsuwan et al., 2009;). 


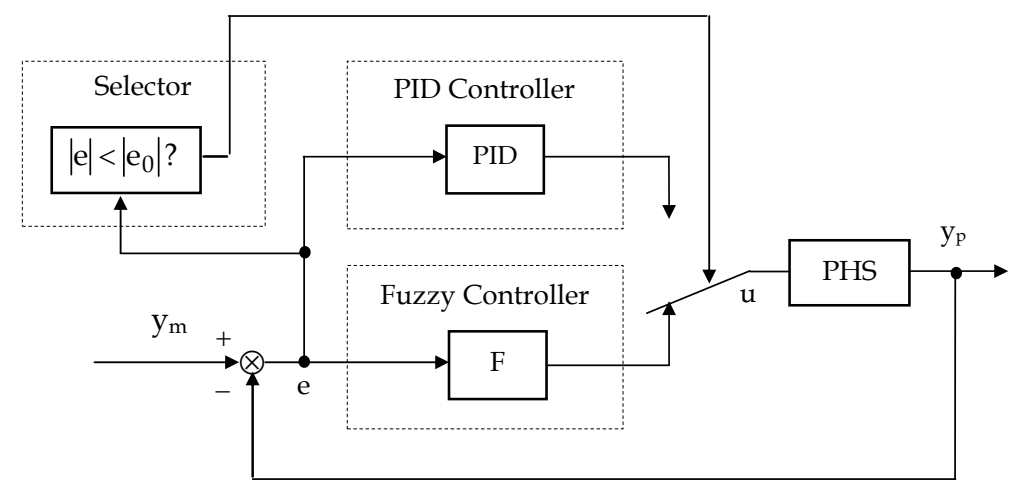

Fig. 9. Block diagram of a hybrid fuzzy PID controller.

Figure 9 shows a switch between the fuzzy controller and the PID controller, where the position of the switch depends on the error between the actual value and set point value. If the error in position reaches a value higher than that of the threshold $e_{0}$, the hybrid system applies the fuzzy controller, which has a fast rise time and a small amount of overshoot, to the system in order to correct the position with respect to the set point. When the position is below the threshold $e_{0}$ or close to the set point, the hybrid system shifts control to the PID, which has better accuracy near the set position (Parnichkul \& Ngaecharoenkul, 2000; Erenoglu et al., 2006; Pratumsuwan et al., 2009;).

\subsection{Fuzzy pre-compensated PID controller}

Since classical PID controllers are widely used in industrial applications, they exhibit poor performance when applied to the PHS containing unknown nonlinearities, such as dead zones, saturation, and hysteresis. In this section, we will describe a fuzzy logic-based precompensation design for PID controllers (Kim et al., 1994)

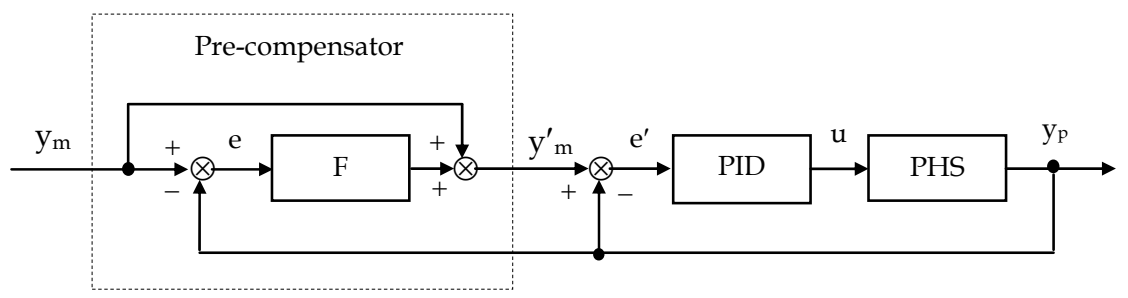

Fig. 10. Block diagram of fuzzy pre-compensated PID controller.

Figure 10 illustrates the basic control structure. The scheme consists of a classical PID control structure together with fuzzy pre-compensator. The fuzzy pre-compensator uses the command input $y_{m}$ and the PHS output $y_{p}$ to generate a pre-compensated command signal $\mathrm{y}^{\prime} \mathrm{m}$, described by the following equations (Kim et al., 1994). 


$$
\begin{aligned}
\mathrm{e}(\mathrm{k}) & =\mathrm{y}_{\mathrm{m}}(\mathrm{k})-\mathrm{y}_{\mathrm{p}}(\mathrm{k}) \\
\Delta \mathrm{e}(\mathrm{k}) & =\mathrm{e}(\mathrm{k})-\mathrm{e}(\mathrm{k}-1) \\
\mu(\mathrm{k}) & =\mathrm{F}[\mathrm{e}(\mathrm{k}), \Delta \mathrm{e}(\mathrm{k})] \\
\mathrm{y}_{\mathrm{m}}^{\prime}(\mathrm{k}) & =\mathrm{y}_{\mathrm{m}}(\mathrm{k})+\mu(\mathrm{k})
\end{aligned}
$$

In the above, $e(k)$ is the position error between the command input $y_{m}(k)$ and the PHS output $y_{p}(k)$ and $\Delta e(k)$ is the change in position error. The term $F[e(k), \Delta e(k)]$ is a nonlinear mapping of $e(k)$ and $\Delta e(k)$ based on fuzzy logic. The term $\mu(k)=[e(k), \Delta e(k)]$ represents a compensation or correction term, so that the compensated command signal $y_{m}^{\prime}(k)$ is simply the sum of the external command signal $y_{m}(k)$ and $\mu(k)$. The correction term is based on the error $e(k)$ and the change of error $\Delta e(k)$. The compensated command signal $y_{m}^{\prime}(k)$ is applied to a classical PID scheme, as shown in figure 10.

The equations governing the PID controller are as follows

$$
\begin{aligned}
\mathrm{e}^{\prime}(\mathrm{k}) & =\mathrm{y}_{\mathrm{m}}^{\prime}(\mathrm{k})-\mathrm{y}_{\mathrm{p}}(\mathrm{k}) \\
\Delta \mathrm{e}^{\prime}(\mathrm{k}) & =\mathrm{e}^{\prime}(\mathrm{k})-\mathrm{e}^{\prime}(\mathrm{k}-1) \\
\mathrm{u}(\mathrm{k}) & =\mathrm{u}(\mathrm{k}-1)+\mathrm{K}_{\mathrm{P}} \Delta \mathrm{e}^{\prime}(\mathrm{k})+\mathrm{K}_{\mathrm{I}} \mathrm{e}^{\prime}(\mathrm{k})+\mathrm{K}_{\mathrm{D}}\left(\Delta \mathrm{e}^{\prime}(\mathrm{k})-\Delta \mathrm{e}^{\prime}(\mathrm{k}-1)\right)
\end{aligned}
$$

The quantity $e^{\prime}(k)$ is the pre-compensated position error between the pre-compensated command input $y_{m}^{\prime}(k)$ and PHS output $y_{p}(k)$, and $\Delta e^{\prime}(k)$ is the change in the pre-compensated position error. The control $u(k)$ is applied to the input of the PHS. The purpose of the fuzzy pre-compensator is to modify the command signal to compensate for the overshoots and undershoots present in the output response when the PHS has unknown nonlinearities.

For PID tuning in this paper, we set PID gains with Ziegler-Nichols and trial-error method.

The purpose of the fuzzy pre-compensator is to modify the command signal to compensate for the overshoots and undershoots present in the output response when the PHS has unknown nonlinearities. An expert's experience and knowledge method is used to build a rule base and membership functions (Rahbari \& Silva, 2000).

In our description, we think of $e(k)$ and $\Delta e(k)$ as inputs, and $\mu(k)$ as the output. The fuzzy states of the inputs and the output, all are chosen to be equal in number and use the same linguistic descriptors : $\mathrm{NB}=$ negative big, $\mathrm{NM}=$ negative medium, $\mathrm{NS}=$ negative small, $\mathrm{ZO}$ = zero, $\mathrm{PS}=$ positive small, $\mathrm{PM}=$ positive medium, and $\mathrm{PB}=$ positive big. (The fuzzy sets is shown in figure 11.) The decision-making output can be obtained using a max-min fuzzy inference where the crisp output is calculated by the center of gravity (COG) method.

Using these fuzzy sets, the fuzzy rules can be designed. The designed rules are presented in table 2. To explain how these rules were obtained, consider for example the rules in table 2. Suppose that the command signal is a constant $y_{m}$, the error $e(k)$ is zero, and the change of error $\Delta e(k)$ is a negative number. This mean that the output $y_{p}(k)=y_{m}-e(k)$ is increasing, i.e., heading in the direction of an overshoot. To compensate for this, we decrease the command signal. This corresponds to applying a correction term $\mu(k)$ that is negative. Hence, we get the rule "if error is zero and change of error is negative medium, then output a negative big correction term". 

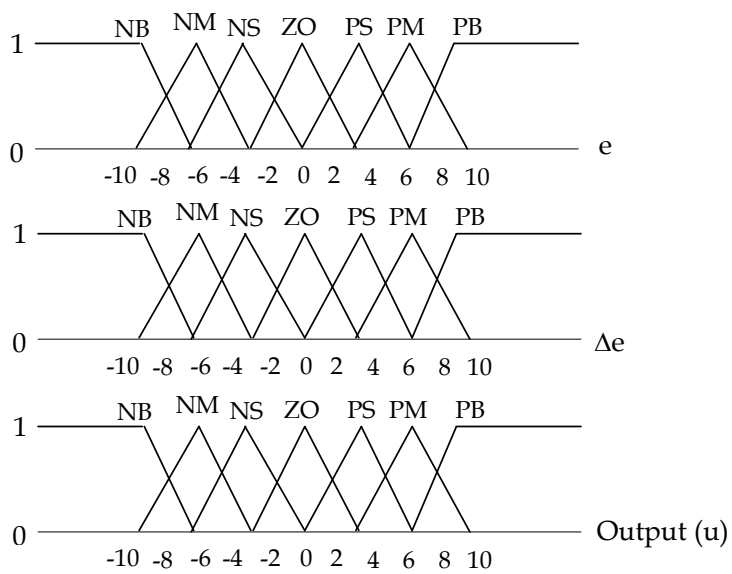

Fig. 11. The fuzzy sets of a pre-compensator.

\begin{tabular}{|c|c|c|c|c|c|c|c|}
\hline $\mathrm{e} \Delta \mathrm{e}$ & $\mathrm{NB}$ & $\mathrm{NM}$ & $\mathrm{NS}$ & ZO & PS & PM & PB \\
\hline NB & & NB & NB & NB & NM & & \\
\hline NM & & & & NM & NM & & \\
\hline NS & & & & NS & PS & & PM \\
\hline ZO & NB & NB & NM & ZO & PS & PM & PM \\
\hline PS & NB & NB & NM & PS & PM & PB & PB \\
\hline PM & & & NM & PM & & PB & \\
\hline PB & & & PM & PB & & & \\
\hline
\end{tabular}

Table 2. Fuzzy rules of a pre-compensator.

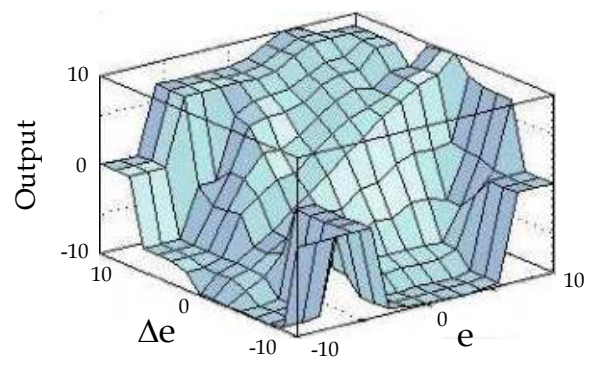

Fig. 12. Input-output mapping of a pre-compensator.

\subsection{Two-layered fuzzy logic controller}

In this section we describe a fuzzy pre-compensated fuzzy controller or a two-layered fuzzy logic controller (Kim et al., 1994; Pratumsuwan \& Thongchai, 2009). The aim is to eliminate the steady state error and improve the performance of the output response for control systems with dead zones. 


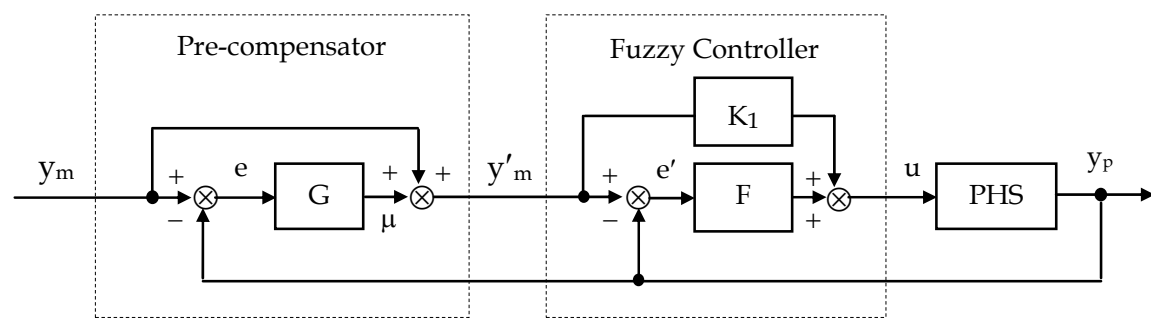

Fig. 13. Block diagram of a two-layered fuzzy logic controller.

We now proceed to describe the proposed controller. First, define the variables $y_{m}^{\prime}(k)$ and $e^{\prime}(k)$ as follows :

$$
\begin{aligned}
y_{m}^{\prime}(k) & =y_{m}(k)+\mu(k) \\
e^{\prime}(k) & =e(k)+\mu(k)
\end{aligned}
$$

where $\mu(k)$ is a compensating term which is generated using a fuzzy logic scheme, which we will describe below. The proposed control scheme is shown in figure 13. The controller consists of two "layers" : a fuzzy pre-compensator, and a usual fuzzy PD controller. Hence we refer to the scheme as a two-layered fuzzy logic controller. The error $e(k)$, and change of error $\Delta e(k)$, are inputs to the pre-compensator. The output of the pre-compensator is $\mu(k)$. The dynamics of overall system is then described by the following equations:

$$
\begin{aligned}
\mathrm{e}(\mathrm{k}) & =\mathrm{y}_{\mathrm{m}}(\mathrm{k})-\mathrm{y}_{\mathrm{p}}(\mathrm{k}) \\
\Delta \mathrm{e}(\mathrm{k}) & =\mathrm{e}(\mathrm{k})-\mathrm{e}(\mathrm{k}-1) \\
\mathrm{\mu}(\mathrm{k}) & =\mathrm{G}[\mathrm{e}(\mathrm{k}), \Delta \mathrm{e}(\mathrm{k})] \\
\mathrm{y}_{\mathrm{m}}^{\prime}(\mathrm{k}) & =\mathrm{y}_{\mathrm{m}}(\mathrm{k})+\mu(\mathrm{k}) \\
\mathrm{e}^{\prime}(\mathrm{k}) & =\mathrm{y}_{\mathrm{m}}^{\prime}(\mathrm{k})-\mathrm{y}_{\mathrm{p}}(\mathrm{k}) \\
\Delta \mathrm{e}^{\prime}(\mathrm{k}) & =\mathrm{e}^{\prime}(\mathrm{k})-\mathrm{e}^{\prime}(\mathrm{k}-1) \\
\mathrm{u}(\mathrm{k}) & =\mathrm{K}_{1} \mathrm{y}_{\mathrm{m}}^{\prime}(\mathrm{k})+\mathrm{F}\left[\mathrm{e}^{\prime}(\mathrm{k}), \Delta \mathrm{e}^{\prime}(\mathrm{k})\right]
\end{aligned}
$$

where $K_{1}$ is the feed forward gain.

\section{Pre-compensation of a Hybrid Fuzzy PID Controller}

Pre-compensation of a hybrid fuzzy PID controller, as shown in figure 14, was developed to combine the advantages of both fuzzy pre-compensated PID controller and fuzzy precompensated fuzzy controller, which described in section 2.3, 2.4, and 2.5.

Figure 14 shows a switch between the fuzzy controller and the PID controller, where the position of the switch depends on the error between the actual value and set point value. If the error in PHS reaches a value higher than that of the threshold $e_{0}$, the control system applies the fuzzy controller, which has a fast rise time and a small amount of overshoot, to the system in order to correct the position with respect to the set point. When the position is 
lower the threshold $e_{0}$ or close to the set point, the control system shift switch to the PID controller, which has better accuracy near the set point.

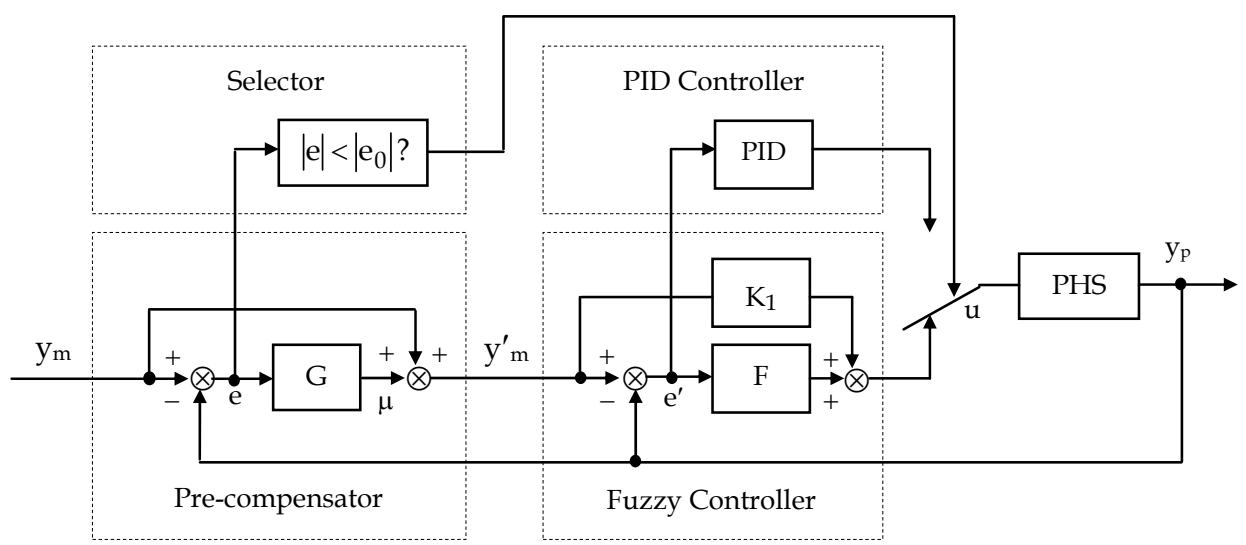

Fig. 14. Block diagram of pre-compensation of a hybrid Fuzzy PID controller.

\section{Experimental Description}

The specifications of a PHS are depicted in figures. 15, 16 and table 3 respectively. Figure 15 shows a diagram of the tested system. The position control of a PHS procedure is described as follows: upon the intended initial and ending position of the piston (stroke) are given, the computer receives the feedback signal through DAQ card (A/D) from linear potentiometer, realizes various control algorithm and transmits a control signal through DAQ card (D/A) and amplifier card to proportional valve. The spool displacement of proportional valve is proportional to the input signal.

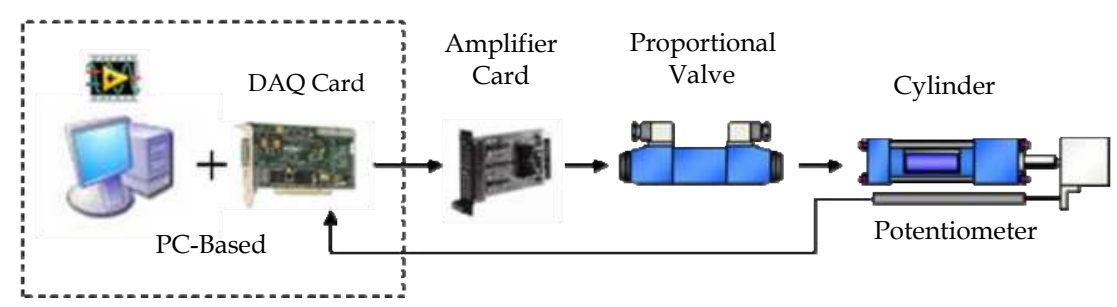

Fig. 15. PC-Based position control of a PHS. 


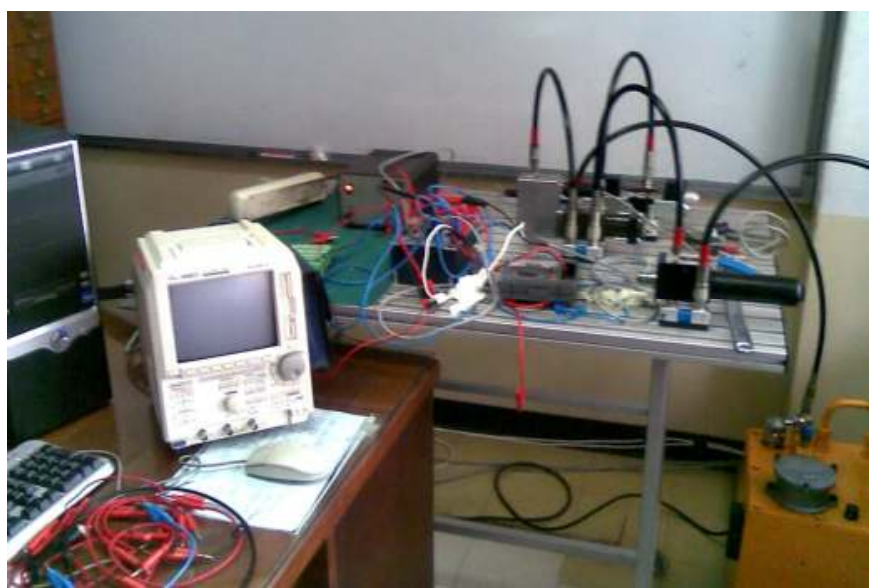

Fig. 16. The experimental setup.

\begin{tabular}{|c|c|}
\hline Elements & Descriptions \\
\hline Cylinder & $\begin{array}{l}\text { piston diameter } 16 \mathrm{~mm} \text {, piston rod diameter } 10 \mathrm{~mm} \text {, } \\
\text { stroke } 200 \mathrm{~mm}\end{array}$ \\
\hline $\begin{array}{l}\text { Proportional valve } \\
\text { ( } 4 / 3 \text { closed-center } \\
\text { spool, overlapped })\end{array}$ & $\begin{array}{l}\text { directly actuated spool valve, grade of filtration } 10 \mu \mathrm{m} \text {, } \\
\text { nominal flow rate } 1.51 / \mathrm{min} \quad\left(\text { at } \Delta \mathrm{p}_{\mathrm{N}}=5 \mathrm{bar} / \text { control }\right. \\
\text { edge), leakage oil flow }<0.01 \mathrm{l} / \mathrm{min} \text { (at } 60 \mathrm{bar}), \text { nominal } \\
\text { current } 680 \mathrm{~mA} \text {, resolution }<1 \mathrm{~mA} \text {, setting time of signal } \\
\text { jump } 0 \ldots 100 \%=60 \mathrm{~ms} \text {, repetition accuracy }<1 \%\end{array}$ \\
\hline $\begin{array}{l}\text { Pump } \\
\text { (supply pressure) }\end{array}$ & 60 bar \\
\hline Linear potentiometer & $\begin{array}{l}\text { output voltage } 0 \ldots 10 \mathrm{~V} \text {, measuring stroke } 200 \mathrm{~mm} \text {, } \\
\text { linearity tolerance } 0.5 \%\end{array}$ \\
\hline Amplifier card & $\begin{array}{l}\text { set point values } \pm 10 \mathrm{VDC} \text {, solenoid outputs (PWM signal) } \\
24 \mathrm{~V} \text {, dither frequency } 200 \mathrm{~Hz} \text {, max current } 800 \mathrm{~mA} \text {, }\end{array}$ \\
\hline $\begin{array}{l}\text { DAQ Card } \\
\text { (NI } 6221 \mathrm{PCI})\end{array}$ & $\begin{array}{l}\text { analog input resolutions } 16 \text { bits (input range } \pm 10 \mathrm{~V} \text { ), } \\
\text { output resolutions } 16 \text { bits (output range } \pm 10 \mathrm{~V}), 833 \mathrm{kS} / \mathrm{s}(6 \\
\mu \text { s full-scale settling) }\end{array}$ \\
\hline $\begin{array}{l}\text { Operating systems \& } \\
\text { Program }\end{array}$ & Windows XP, and LabVIEW 8.6 \\
\hline
\end{tabular}

Table 3. Specifications of a PHS.

\section{The Experimental Results}

The control algorithms described in section 2.3, 2.4, and 2.5 were hybridized and applied to the PHS using by LabVIEW, Nation Instruments as the development platform and shown in figure 17. 


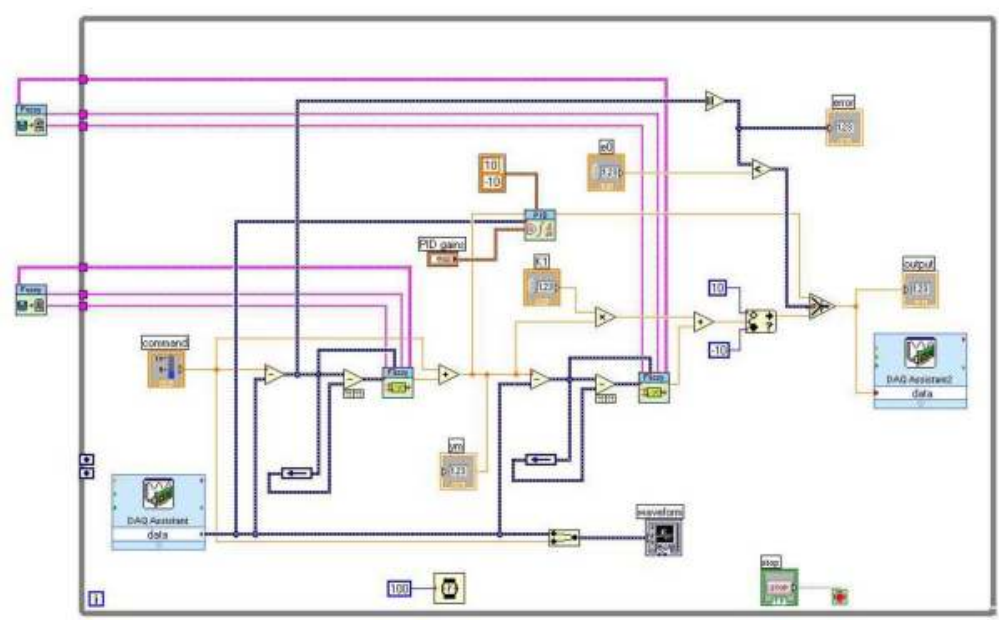

Fig. 17. The control algorithm are used and developed by LabVIEW program.

In our experiments we compare the performance of conventional hybrid fuzzy PID controller to the proposed pre-compensation of a hybrid fuzzy PID controller. A testing of response of the system was performed using a square wave input. The parameter values of the pre-compensation of a hybrid fuzzy PID controller were experimentally determined to be: $K_{1}=0.93, K_{P}=5.6, e_{0}=0.92$. Figures. 18 and 19 shows the output response of a conventional hybrid fuzzy PID system compared to the pre-compensation of a hybrid fuzzy PID system. It is found that the pre-compensation of a hybrid fuzzy PID controller gives the most satisfying results of rise time, overshoot, and steady state error.

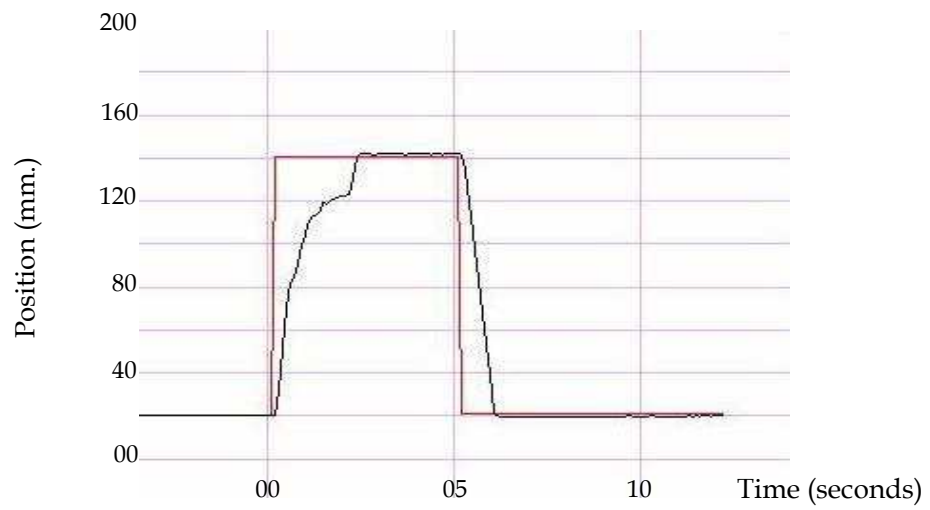

Fig. 18. Output response of conventional (hybrid fuzzy PID) controller. 


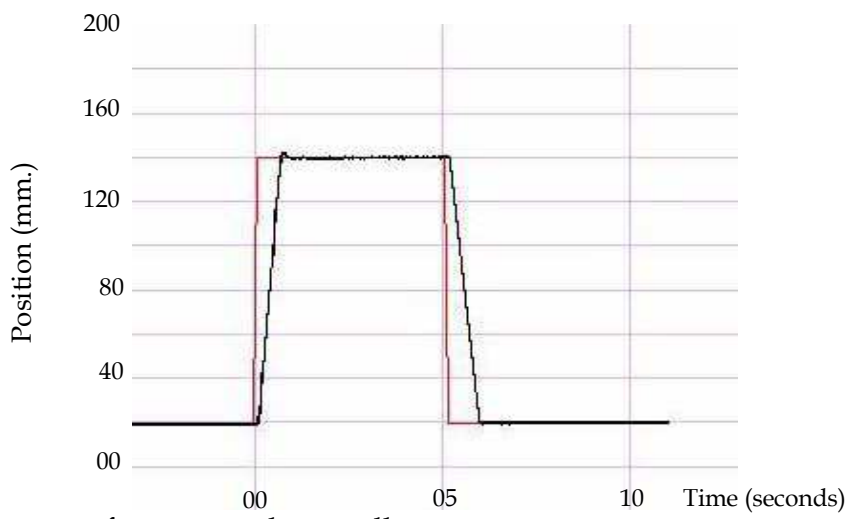

Fig. 19. Output response of a proposed controller.

\section{Conclusions}

The objective of this study, we proposed the pre-compensation of a hybrid fuzzy PID controller for a PHS with deadzones. The controller consists of a fuzzy pre-compensator followed by fuzzy controller and PID controller. The proposed scheme was tested experimentally and the results have superior transient and steady state performance, compared to a conventional hybrid fuzzy PID controller. An advantage of the present approach is that an existing hybrid fuzzy PID controller can be easily modified into the control structure by adding a fuzzy pre-compensator, without having to retune the internal variables of the existing hybrid fuzzy PID controller.

In this study, an experimental research, so we do not address the problem of analyzing the stability of the control scheme in this paper. This difficult but important problem is a topic of ongoing research.

\section{References}

Chin-Wen Chuang and Liang-Cheng Shiu.(2004). CPLD based DIVSC of hydraulic position control systems. Computers and Electrical Engineering. Vol.30, pp.527-541.

T. Knohl and H. Unbehauen. (2000). Adaptive position control of electrohydraulic servo systems using ANN. Mechatronics. Elsevier Science Ltd. vol. 10, pp. 127-143.

Bora Eryilmaz, and Bruce H. Wilson. (2006). Unified modeling and analysis of a proportional valve. Journal of the Franklin Institute, pp. 48-68.

L.A. Zadeh. (1965). Fuzzy sets. Information and Control. vol.8, pp.338-1588.

E.H. Mandani and S. Assilian. (1975). An experiment in linquistic synthsis with a fuzzy logic control. Machine Studies. vol.7, pp. 1-13.

Isin Erenoglu, Ibrahim Eksin, Engin Yesil, and Mujde Guzelkaya. (2006). An Intelligent Hybrid Fuzzy PID Controller," Proceedings $20^{\text {th }}$ European Conference on Modelling and Simulation @ ECMS. ISBN : 0-9553018-0-7.

Roya Rahbari, and Clarence W. de Silva. (2000). Fuzzy Logic Control of a Hydraulic System. OIEEE, ISBN: 0-7803-58112-0, pp. 313-318. 
M. Parnichkul and C. Ngaecharoenkul. (2000). Hybrid of Fuzzy and PID in Kinematics of a Pneumatic System. Proceeding of IEEE Industrial Electronics Society. IEEE Press, vol. 2 no. 2, pp.1485-1490.

Hao Liu, Jae-Cheon Lee, and Bao-Ren Li. (2007). High Precision Pressure Control of a Pneumatic Chamber using a Hybrid Fuzzy PID Controller. International Journal of Precision Engineering and Manufacturing, Vol.8, No3. pp. 8-13.

Jong-Hwan Kim, Kwang-Choon Kim, and Edwin K.P. Chong. (1994). Fuzzy Precompensated PID Controllers. IEEE Transactions on Control System Technology, Vol.2, No. 4, December, pp. 406-411.

J.-H. Kim, J.-H. Park, S.-W. Lee, E.K.P. Chong. (1994). A Two-Layered Fuzzy Logic Controller for Systems with Deadzones," IEEE Transactions on Industrial Electronics, Vol. 41, No. 2, April. pp. 155-162.

Chang-chun Li, Xiao-dong Liu, Xin Zhou, Xuan Bao, Jing Huang. (2006). Fuzzy Control of Electro-hydraulic Servo Systems Based on Automatic Code Generation. Proceedings of the Sixth International Conference on Intelligent Systems Design and Applications (ISDA'06).

Pornjit Pratumsuwan, and Siripun Thongchai. (2009). A Two-Layered Fuzzy Logic Controller for Proportional Hydraulic System. Proceeding of $4^{\text {th }}$ IEEE International Conference on Industrial Electronic and Applications (ICIEA2009), pp. 2778-2781.

Pornjit Pratumsuwan, Siripun Thongchai, and Surapun Tansriwong. (2010). A Hybrid of Fuzzy and Proportional-Intrgral-Derivative Controller for Electro-Hydraulic Position Servo System. Energy Research Journal 1(2), pp.62-67. 


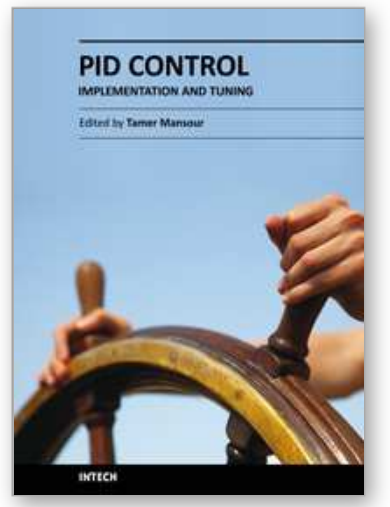

\author{
PID Control, Implementation and Tuning \\ Edited by Dr. Tamer Mansour
}

ISBN 978-953-307-166-4

Hard cover, 238 pages

Publisher InTech

Published online 19, April, 2011

Published in print edition April, 2011

The PID controller is considered the most widely used controller. It has numerous applications varying from industrial to home appliances. This book is an outcome of contributions and inspirations from many researchers in the field of PID control. The book consists of two parts; the first is related to the implementation of PID control in various applications whilst the second part concentrates on the tuning of PID control to get best performance. We hope that this book can be a valuable aid for new research in the field of PID control in addition to stimulating the research in the area of PID control toward better utilization in our life.

\title{
How to reference
}

In order to correctly reference this scholarly work, feel free to copy and paste the following:

Pornjit Pratumsuwan and Chaiyapon Thongchaisuratkrul (2011). Pre-compensation for a Hybrid Fuzzy PID Control of a Proportional Hydraulic System, PID Control, Implementation and Tuning, Dr. Tamer Mansour (Ed.), ISBN: 978-953-307-166-4, InTech, Available from: http://www.intechopen.com/books/pid-controlimplementation-and-tuning/pre-compensation-for-a-hybrid-fuzzy-pid-control-of-a-proportional-hydraulicsystem

\section{INTECH}

open science | open minds

\section{InTech Europe}

University Campus STeP Ri Slavka Krautzeka 83/A 51000 Rijeka, Croatia

Phone: +385 (51) 770447

Fax: +385 (51) 686166 www.intechopen.com

\section{InTech China}

Unit 405, Office Block, Hotel Equatorial Shanghai

No.65, Yan An Road (West), Shanghai, 200040, China 中国上海市延安西路65号上海国际贵都大饭店办公楼 405 单元 Phone: +86-21-62489820

Fax: +86-21-62489821 
(C) 2011 The Author(s). Licensee IntechOpen. This chapter is distributed under the terms of the Creative Commons Attribution-NonCommercialShareAlike-3.0 License, which permits use, distribution and reproduction for non-commercial purposes, provided the original is properly cited and derivative works building on this content are distributed under the same license. 